\title{
ACADEMIC MOTIVATION OF STUDENTS IN PHYSICAL EDUCATION AND SPORT AT SOFIA UNIVERSITY "ST. KLIMENT OHRIDSKI“"
}

\author{
G. Ignatov ${ }^{1 *}$, I. Petkova ${ }^{2} * *$ \\ ${ }^{1}$ Department of Sport, Sofia University "St. Kliment Ohridski”, Sofia, Bulgaria \\ ${ }^{2}$ Faculty of Education, Sofia University "St. Kliment Ohridski”, Sofia, Bulgaria
}

\begin{abstract}
Training is a two-way process of pedagogical interaction. The quality of the final result depends not only on the teacher, but also on the academic motivation of students participating as equal partners in the educational process. The PURPOSE of this article is to represent the results from a study aimed at establishing the degree of academic motivation of students. Total of 45 participants (of which 26 male and 19 female students) were questioned. All of them were in the second and third year of their bachelor study in the specialty Physical Education and Sport at Sofia University "St. Kliment Ohridski". METHODS: As an instrument is used Angel Velichkov's questionnaire for evaluation of the level of academic motivation in which are set the factors that favour or impede the formation of high academic motivation and also allows to trace its development. RESULTS: Results are aimed at proving the hypotheses. We assume that the students in Physical Education and Sport specialty should have: 1) an active attitude towards the learning process; 2) internal self-discipline and 3) a striving to complete and extend the knowledge obtained. The analysis will be comparative, based on the gender and year of study which will allow us to determine whether these two criteria also influence the degree of academic motivation. CONCLUSION: The establishment of differences in the levels on these three criteria and the overall level of the students' academic motivation will enable teachers to optimize the teaching process and make it more personal-oriented.
\end{abstract}

Key words: academic motivation, higher education, student in speciality „Physical educational and sport“"

\section{INTRODUCTION}

One of the key concepts when talking about professional activity is quality. It is measured by different standards, at different stages and levels. In education, a key element is preparation. From it, from its quality, depends on the subsequent successful realization, the opportunities for career development. Excellent preparation is the basis for confident and desirable engagement in the profession. Today, when we talk about a shortage of pedagogical specialists, questions arise not about if we have such specialists, because we have many, but how they are prepared, do they

\footnotetext{
${ }^{*}$ Correspondence to: Georgi Ignatov, PhD; Department of sport, Team sports and mountain sports, Sofia University, address: bul. "Tsar Osvoboditel" 15, 1504 Sofia, Bulgaria, e-mail: gvignatov@uni-sofia.bg, telephone: $+359 / 898773735$

**Correspondence to: Iliana Petkova, PhD; Faculty of Education, Sofia University, address: bul. "Tsar Osvoboditel" 15, 1504 Sofia, Bulgaria, e-mail: i.petkova@fp.uni-sofia.bg, telephone: +359/898 747727
}

feel confident in exercising the difficult and responsible profession of the teacher? The problem of the preparation of future teachers has been the subject of research for every specialist working in different methodological fields. As E. Topolska indicates that "the preparation of bachelor students is a continuous process that begins with gaining knowledge (facts, principles, theories), continues with gaining the ability to apply it (guessing and practical skills) so that eventually there are personal and professional qualities and a proven ability to apply them in working or learning situations (expertise)" (14). P. Marcheva underline also: "The professional and pedagogical training of future teachers stands out as a pressing live question. The requirements for teachers' theoretical and practical training, according to the dynamics of the contemporary educational process are rapidly increasing (9). 
Although in another methodological field physical education, the question about the quality of preparation of future teachers is just as relevant. Except in the National Sports Academy, future teachers of physical culture and sport are prepared and in "Physical education and sport" at the Faculty of Educational Science and Arts (FNOI) of Sofia University "St. Kliment Ohridski". This specialty is just 10 years old and academically is ensured both by professors from the faculty, but also by specialists from the Department of Sports at the University. As G. Ignatov points out, one of these experts, "The study of the two-tier process "teacher-student" cannot give a full picture of what is happening in the specialty but can clarify many very important issues related to the organization and training of students, to check the objectives and, last but not least, to give a clear idea of the students' attitude towards the lecturers in Physical education and sports" (5).

After a research, I. Petkova points out that "the specialty "Physical education and sport" is a desired specialty. It attracts and retains its students with the right balance between theory and practice, the good relationship between lecturers and students, with the satisfaction of the training it offers" (12).

According to I. Peltekova, "motivation and positive attitude are important for achieving the goals of physical education and sport among students“"(10).

For E. Djambazova and E. Marinova, the commitment to build skills in the students, future teachers of physical education, remains for the teachers in the higher schools and the students themselves, motivated by the great competition in job searching (2).

In such a context is the publication of $\mathrm{V}$. Ivanova. The focus is on the purposeful development of reflection among future teachers, understood in the terms of the pedagogical methodical competence for the effective realization of motor training (8).

For active participation in physical education and sport, the satisfaction of the purposeful motor activity is also decisive. It is not enough just to attend classes as a compulsory course. The effectiveness depends on meeting the needs of a positive mood and physical unloading, obtaining knowledge, developing skills, grooming, achieving good physical shape and guidance on healthy habits. Making
IGNATOV G., et al. social contacts in a sports environment expands the possibilities for communication, to achieve positive mood and unloading (6).

B. Tumanova argues that the purposeful management of cognitive processes in the process of training creates in the trainees the ability to self-manage. It highlights the guiding principles in ensuring effectiveness: to require the learner to be highly active; to prevent inertness; to seek the development of selfcontrol skills; to engage the complex-personal potential through activities and relationships (15).

According to M. Antonova "the selection of funds activities in physical education should be consistent with the capabilities of those involved so that they can acquire the offered material, but this absorption must be associated with some tension. Otherwise, the learning process will cease to attract them and will contribute to the development of qualities such as perseverance, tenacity, aiming to learn, to enrich the motor skills will be missing" (1).

I. Ilieva and Y. Doncheva emphasize that "the independent or organized practice of various motor activities with a positive effect on the physical development and health of the students also have a bearing on their attitude to physical education and sport" (7).

E. Djambazova and Ev. Penkova perform an interesting study, which takes away and systemizes the qualities of the teacher of physical education and sport, which, according to primary school pupils, are preferred and liked (3).

According to I. Peltekova, "it is important for physical education and sports teachers to acquire scientific knowledge and to learn about theory and methodology but also to be able to confidently demonstrate practical knowledge and skills to the most demanding examiners" (11).

For Zh. Georgiev "increasing the efficiency of physical education and sports education in the higher education institution, should become a major task of the PE lecturers as a prerequisite for improving the physical capacity, the educational success and the healthy lifestyle of the students" (4).

The above-mentioned opinions required a study aimed at studying the academic motivation of the students of the Physical Education and Sport Faculty at the University of Sofia.

The research hypothesis is towards a high level of academic motivation. The specific indicators to be analysed are: 1) active attitude towards the 
learning process, 2) internal self-discipline, and 3 ) the pursuit of completing and expanding the acquired knowledge.

The questionnaire "To assess the level of academic motivation" by author Angel Velichkov was used as a research method. 11 judgments were formulated, 7 of which had positive and 4 negative connotations. The evaluation is done through a 4-step Likert scale,
IGNATOV G., et al. where 0 is completely disagreeable and 3 agrees (13).

The study was conducted at the end of the school year 2016/2017 and all 45 students from the $2^{\text {nd }}$ and $3^{\text {rd }}$ courses of the specialty "Physical education and sport" at the Sofia University "St. Kliment Ohridski" are in the sample group. Their distribution by course and gender is as follows:

Table 1. Distribution of the respondents by course and by gender.

\begin{tabular}{|l|l|l|l|l|l|l|}
\hline Students & \multicolumn{2}{|c|}{ II course } & \multicolumn{2}{c|}{ III course } & \multicolumn{2}{c|}{ Total } \\
\hline Numbers & \multicolumn{2}{|c|}{25} & \multicolumn{2}{c|}{19} & \multicolumn{2}{c|}{44} \\
\hline Gender & 12 females & 14 males & 7 females & 12 males & 19 females & 26 males \\
\hline
\end{tabular}

For A. Velichkov the academic motivation is "understood as a construct describing the general motivational status generated and connected with the education in a specialty at an university. The overall positive motivational readiness is an indicator of the quality of teaching in a given specialty and is also one of the forerunners of academic achievement" (13). The active attitude towards learning, inner self-discipline, and the pursuit of completeness and expansion of the acquired knowledge are one of the manifestations of academic motivation. It is precisely them which are set in the questionnaire and will be analysed in this article. The influence of course and gender factors will also be the subject of scientific interpretation.

Data analysis by indicator of active attitude towards the learning process

The active attitude towards the learning process is reinvented in four statements, two in two opposite - "I'm trying to get a lasting knowledge of all the main disciplines" and "I regularly take notes during lectures" vs "I do not care about the theoretical details in the disciplines" and "Everything we learn here is uninteresting and sometimes I wonder what the meaning of learning is". The results show that the students of both courses are responsible for their learning activities. $61.54 \%$ of students in $2^{\text {nd }}$ course and $84.21 \%$ in $3^{\text {th }}$ course are agree with the statement that they are trying to obtain lasting knowledge in all disciplines studied. Probably the rise in the percentage of $3^{\text {th }}$ course students is due to the fact that in this course narrowly specialized disciplines, related to the preparation of physical culture and sport, are already studied. In this way the learners see much more clearly the connection between their preparation and their importance for the future qualitative realization. $42,11 \%$ of $3^{\text {th }}$ course students also agree that note-taking is important for their academic preparation, and those from the $2^{\text {nd }}$ course are convinced in it $(65,38 \%)$. However, this may also be a sign to teachers that students need textbooks and teaching aids. Shown schematically, the data looks like this:

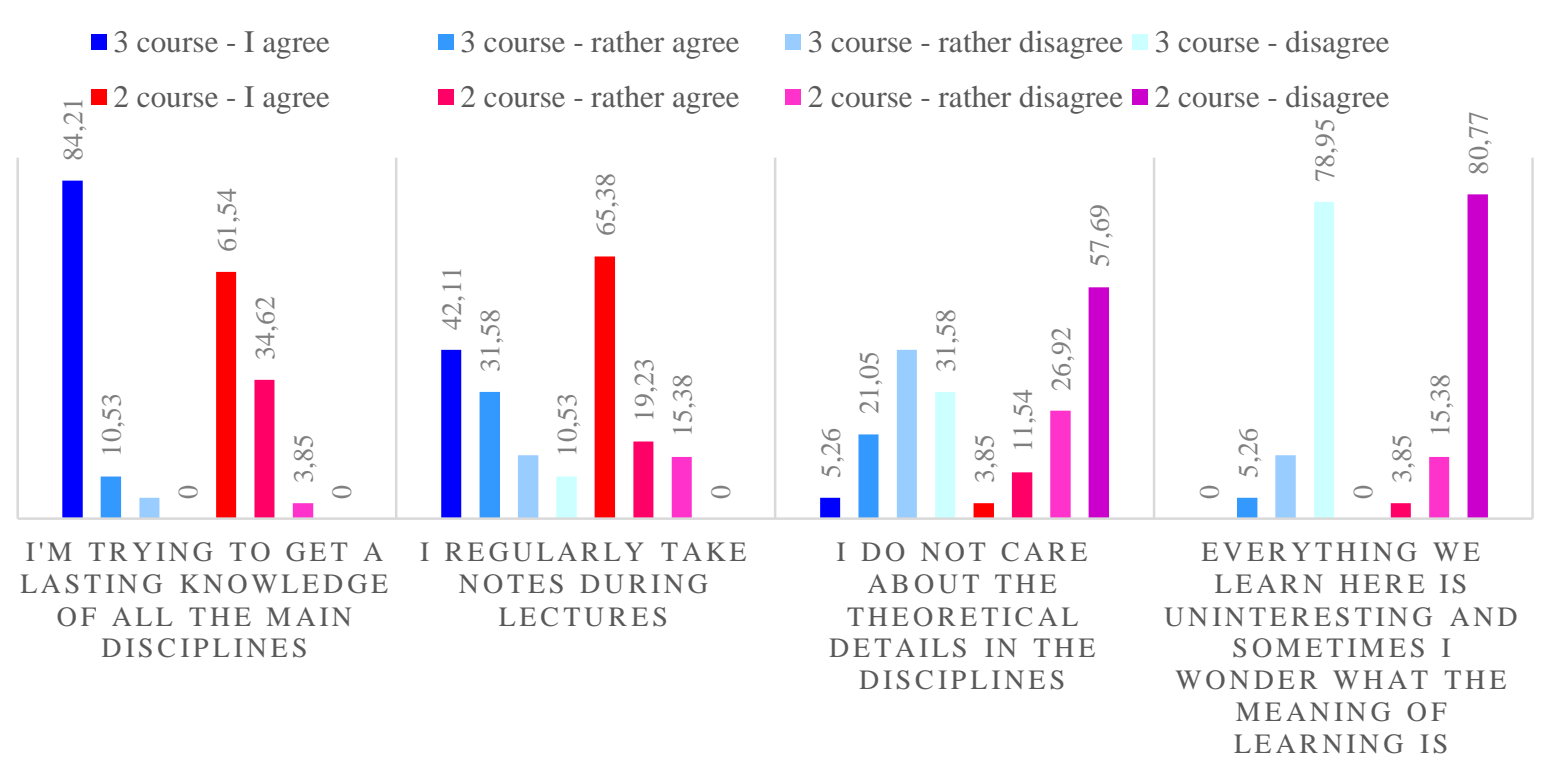

Diagram 1. Results by Indicator Active Attitude to the Learning Process (in\%) 
The analysis of the other two opposing statements shows that $57.69 \%$ of the second-

year students and $31.58 \%$ of the third-year students disagree with the statements that they are not interested in the theoretical training in the disciplines. $80.77 \%$ of $2^{\text {nd }}$ year students and $78.95 \%$ of $3^{\text {rd }}$ year strongly disagree, and all that they learn is uninteresting.

The gender analysis shows that females are more concerned with the learning process is reinforced. $91.67 \%$ of females students in second-year and $71.43 \%$ of females in thirdyear regularly take notes. The $75 \%$ of girls from $2^{\text {nd }}$ course and $28.5 \%$ of those in the 3 year seek to gain lasting knowledge. $36.36 \%$ of
IGNATOV G., et al. males - learners and $81.82 \%$ of males in secondary school reject the statements that they are not interested in the theoretical details in the subjects. At the same time, $50 \%$ of male students in $3^{\text {rd }}$ year and $71.43 \%$ of those in the $2^{\text {nd }}$ year are categorically disagreeing with the statement that everything they teach is uninteresting and sometimes they wonder what the meaning of learning is. The distribution of only "agree" answers to the males and females of both courses shows that they are completely unanimous in their disagreement that they are not interested in the theoretical details in the disciplines and that everything they learn is uninteresting. Implied results look like this:

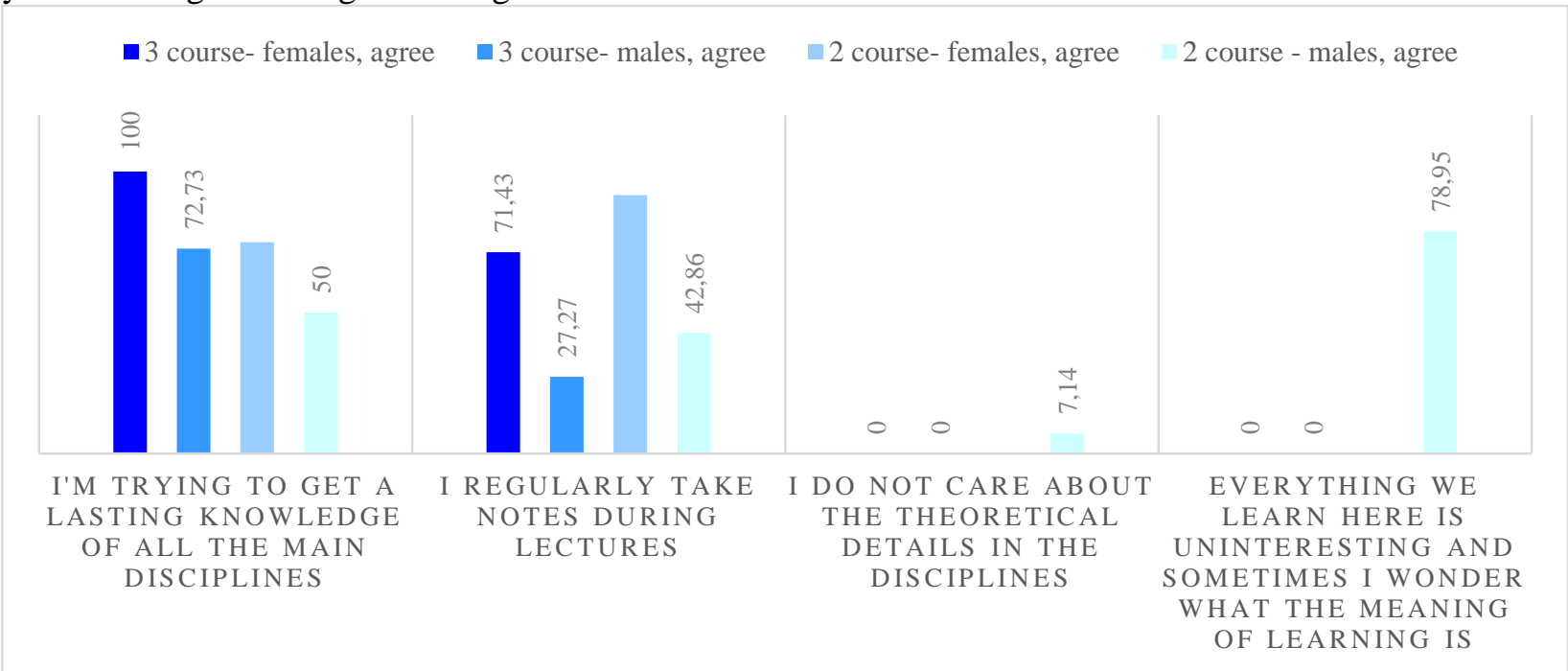

Figure 2. Gender distribution of opinion "I agree" on individual statements to indicator of active attitude to the learning process (in\%)

The summary of this first indicator: an active attitude towards the learning process shows that learners are aware of the need for in-depth theoretical knowledge, taking notes and consider what they are studying in the specialty is interesting and intriguing.

Internal self-discipline is another segment of overall academic motivation. It is "embedded" in three statements - "I want to have great success in all studied disciplines " and "I regularly attend all lectures because I'm interested" vs. "When I'm not interested, I miss lectures and seminars". 94.74\% (52.63\% completely agree and $42.11 \%$ - rather agree) of the third year students are trying to be very successful. This is not so important to secondary school students. Only $30.77 \%$ completely agree, and $46.15 \%$ rather agree with this statement. As a reason for this, we can assume that second year students are not yet aware of the importance of high grade as an indicator and of the level of their preparation. It is likely that they perceive success only as an indicator, but it actually has a bearing on Erasmus + training opportunities, scholarships, when applying for various types of competitions.

For $3^{\text {rd }}$ year students this is already a recognized need. $80.77 \% \quad(26.92 \%$ completely agree and $53.87 \%$ - rather agree) of the second-year students regularly attend lectures due to their interest in the subject matter studied. For third-year students the percentage is $63,16 \%$. Apparently for them the presence of lectures and seminars is no longer of paramount importance. $47.37 \%$ of third-year students are more tolerant and attend classes although they are not interested. However, $53.85 \%$ of the second-year students point out that they would not stay if the classes are held in the same way that does not attract interest and satisfy their curiosity. 


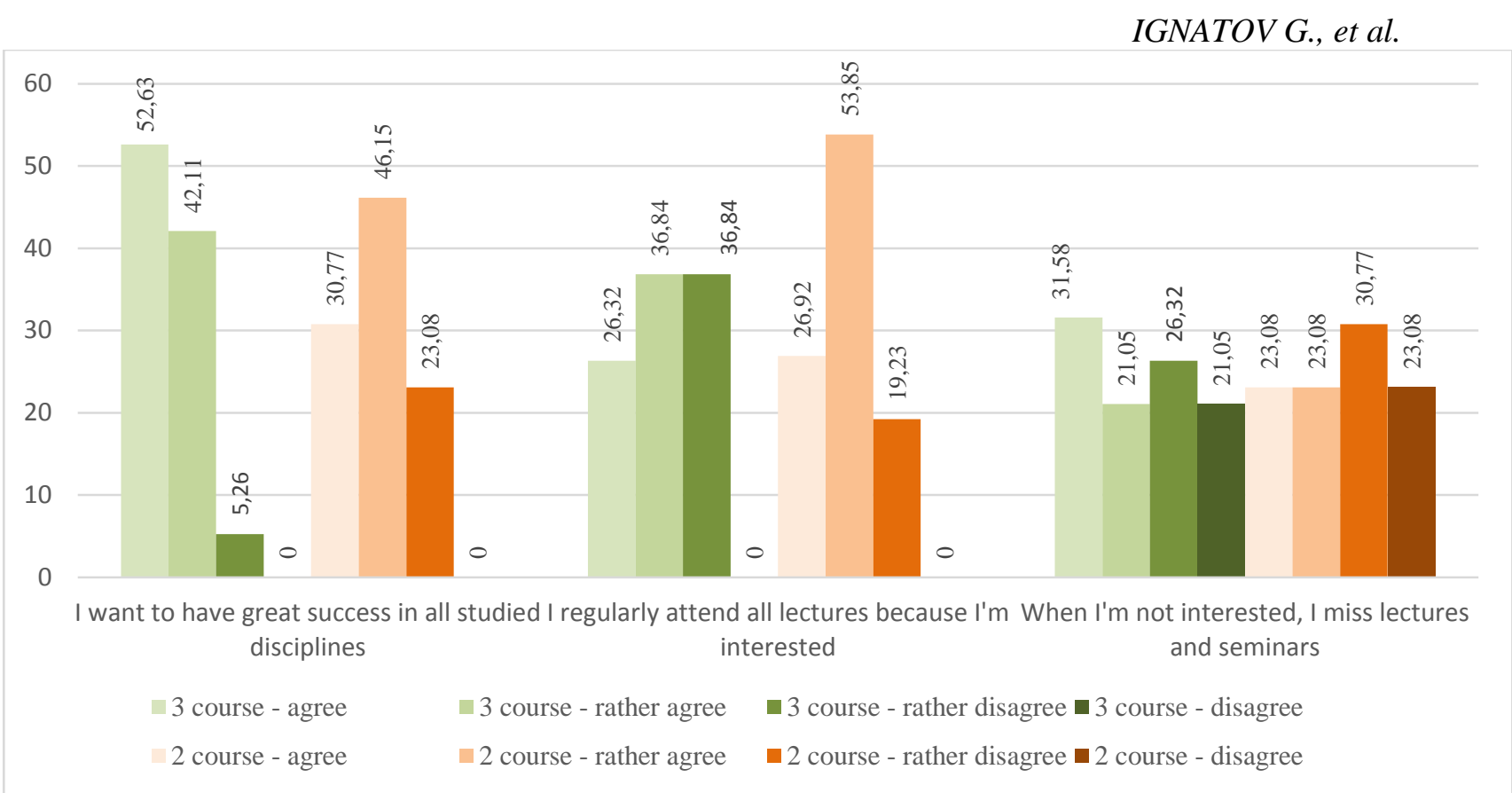

Figure 3. Results by internal self-discipline indicator (in\%)

Gender analysis shows that third-year female students put more emphasis on higher grade. $71.43 \%$ of them are categorical in their agreement that they want to have a high level of grade in the disciplines, compared to male students, where this percentage is $63.64 \%$. This is not the case with the second-year students. There the males agreed $35.71 \%$ and the females - only $25 \%$. If we add to these answers the opinion of those who have given the answer "I rather agree" then the picture changes and the males take a prize. In male third-year students, the percentage is $90 \%$ and for female $-83.72 \%$ and for male second-year students it is $78.57 \%$, compared to $70 \%$ for female students. A total of $83.33 \%$ (33.33\% completely agree and 50\% - rather agree) of second-year students are more likely to take time and attend regular classes. This is not so important for third-year students. However, $71.53 \%$ (42.86\% - agree and $28.57 \%$ - rather agree) of the female students agree with this statement, for males the percentage is $63.63 \%$ (18.18\% - agree and 45, 45\% - rather agree). $54.54 \%$ of third-year male students would compromise and would attend class, even if they are not interested. Second-year male students though would not compromise. $64.64 \%$ of the full and partial agreement say that when they are not interested they miss lectures and seminars. The same way the answers of the female students are distributed. $43.86 \%$ of third-year female students completely or rather agree with the statement, while second-year female students the percentage is $41.67 \%$.

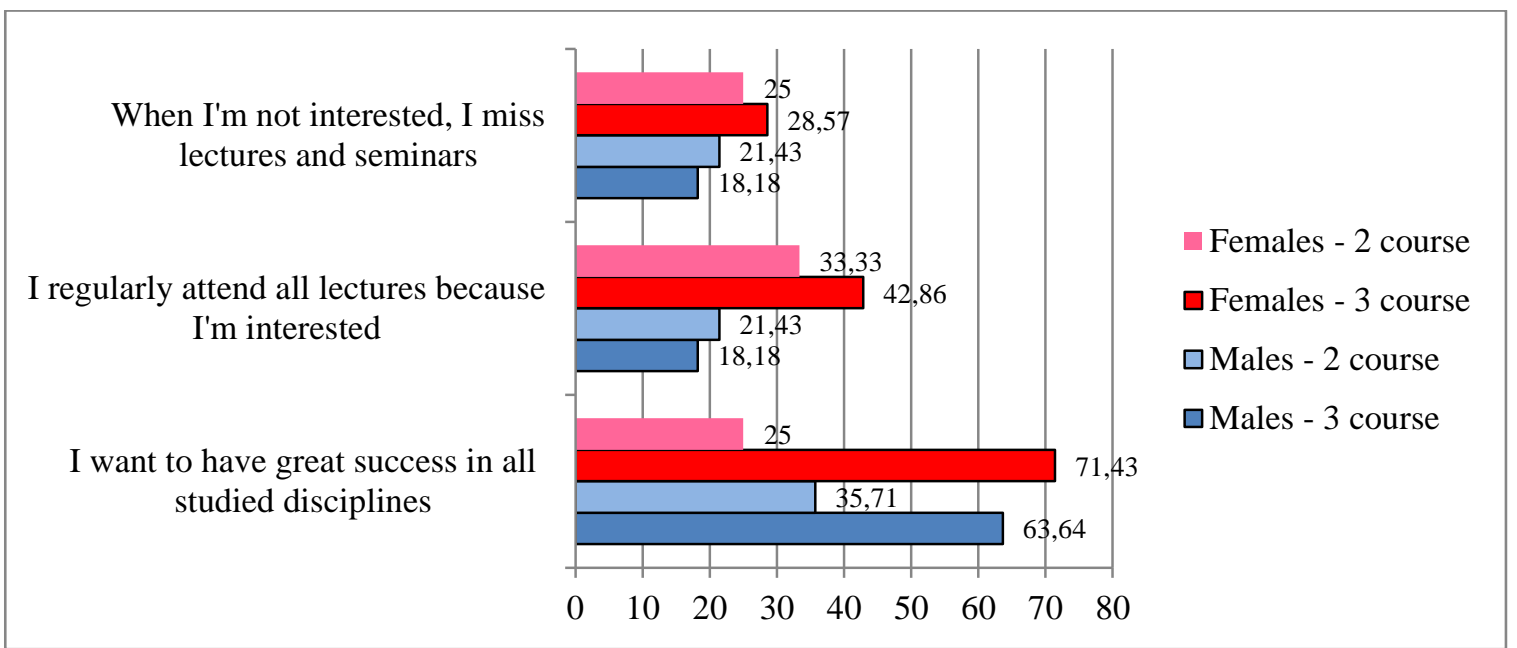

Figure 4. The distribution by year and gender of the response "agree" on individual claims by the second indicator "inner self-discipline" 
The "Attempt to Complete and Expand the Knowledge" indicator is set out in four statements, namely: " I often search for additional literature on learning subjects that interested me", "I often look for additional information from lecturers", and "I regularly visit the library or search additional materials on the Internet" vs "I'm trying to study only within the minimum required". One of the manifestations of a careful attitude towards the learning process is
IGNATOV G., et al. the search for additional literature. However, the question of where this is done - from the teacher himself, the library or the Internet as the source of the information - still stands. Third-year students agree that $63.16 \%$ of them the teachers, then $47,37 \%$ are looking for additional information in the library and $42.11 \%$ admit that they are looking for materials on the Internet. The responses take the following form:

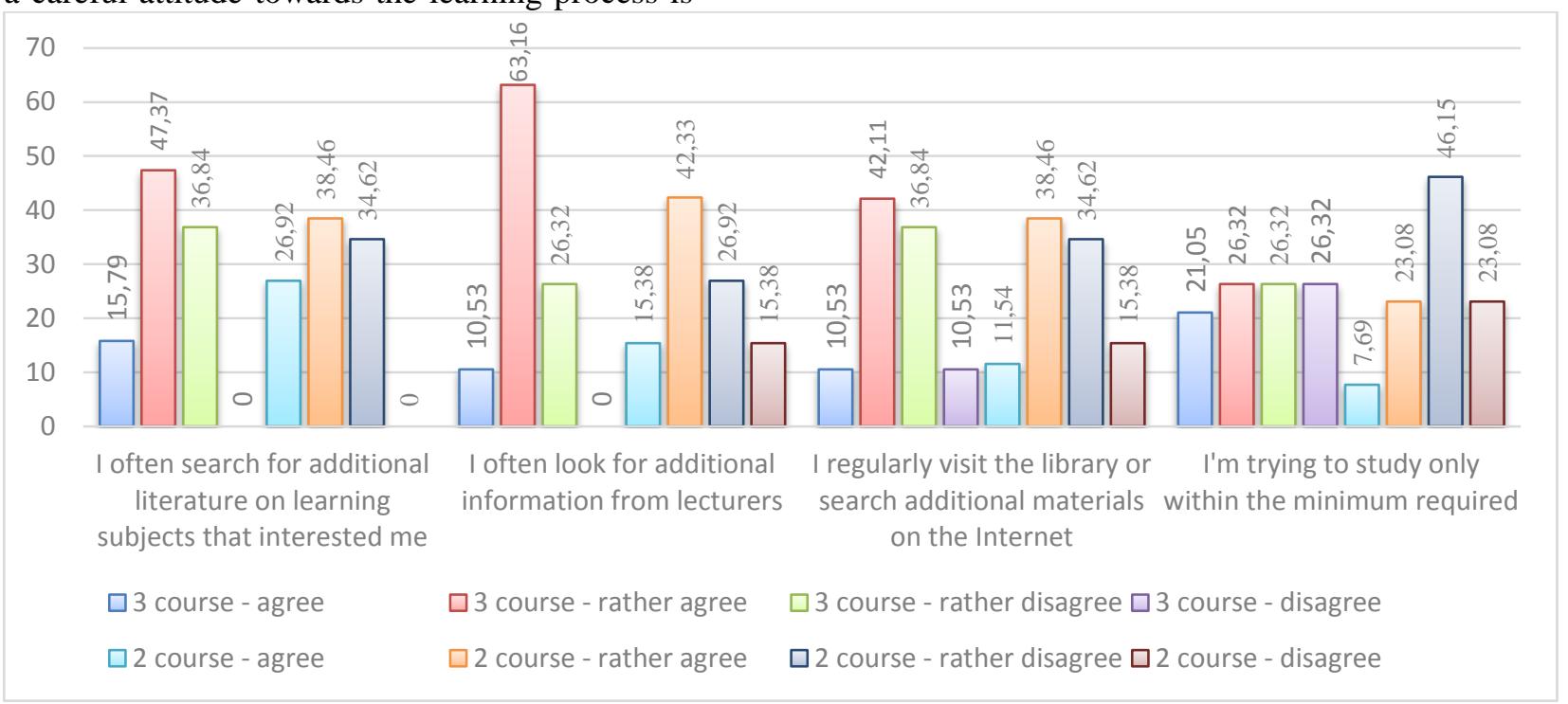

Figure 5. Results by third indicator "Attempt to completing and expanding the knowledge" (in\%)

It should be noted that the percentage of thirdyear students completely agreeing on all three similar claims is low. Similar is the condition of second-year students. $42.31 \%$ of them said they were more likely to agree with the answer that they were looking for additional information from the lecturers. $38.46 \%$ often look for additional literature in the library, and $38.46 \%$ on the Internet. $21.05 \%$ of the thrird-year students agree categorically, and $26.32 \%$ rather agree that they study within the required minimum. For second-year students this percentage is again 7.69\% (agree) and 23.08\% (rather agree). Apparently, both groups of students realize that in order to have a good training they have to learn in depth.

The gender analysis shows that males are more likely to seek information from the teacher. $72.73 \%$ of males in $3^{\text {th }}$ course agree with this statement. $50 \%$ of second-year students are behind it. The percentage $(28.57 \%)$ of females in the third year who strongly agree that they are looking for information both from the library and the Internet, as well as in the disciplines that are interesting to them. For males this percentage it is $7.14 \%$ for second-year regular library attendees. For third-year students this percentage is zero.

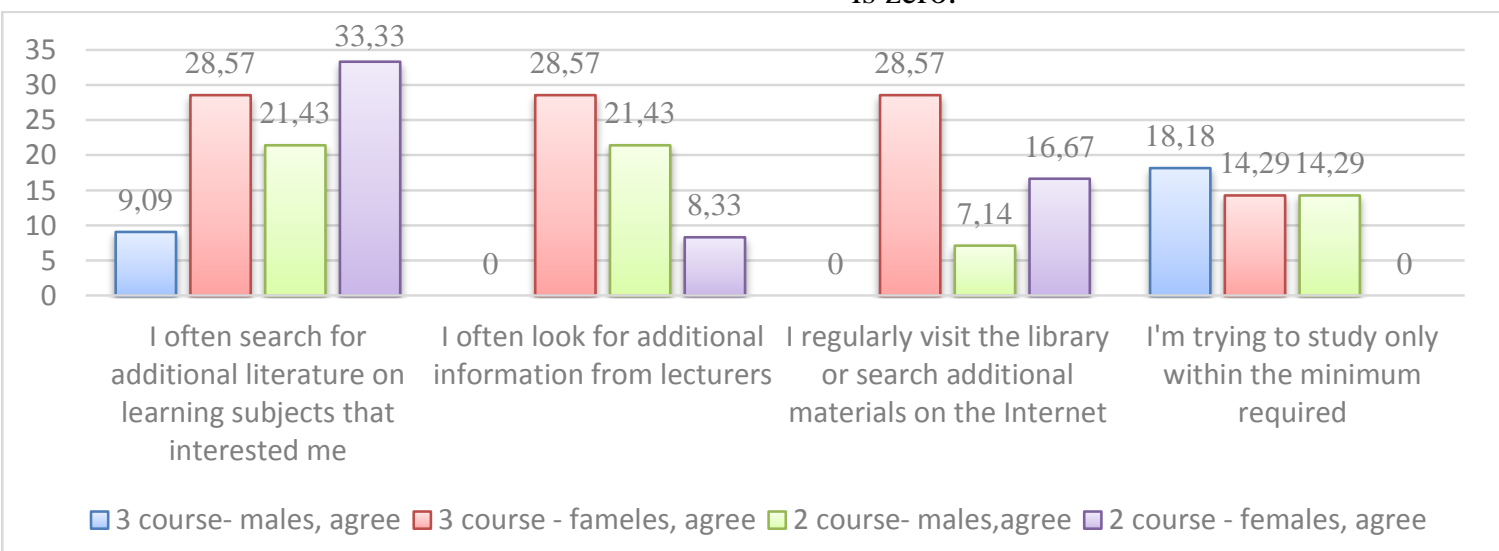

Figure 6. Course and gender distribution of the "I Agree" Response on the individual statements of the Third Indicator "Attempt to Complementing and Expanding the Knowledge" (in\%) 
The analysis of the three indicators suggests that the degree of academic motivation of the students of the 2nd and 3rd year of Physical Education and Sport will be high. However, the summarized picture shows alarming results. M. Radoslavova and A. Velichkov propose a point scale for assessing the degree of academic motivation, namely: 0-11 points absence of academic motivation; $12-18$ points -
IGNATOV G., et al.

weak; 19-24 points - moderate and 25-33 points - strong academic motivation. According to it, in both years the motivation is in the low grade. This applies to both males and females. Only for third-year females it "enters" in the area of moderate motivation. The comparative presentation of the data is as follows:

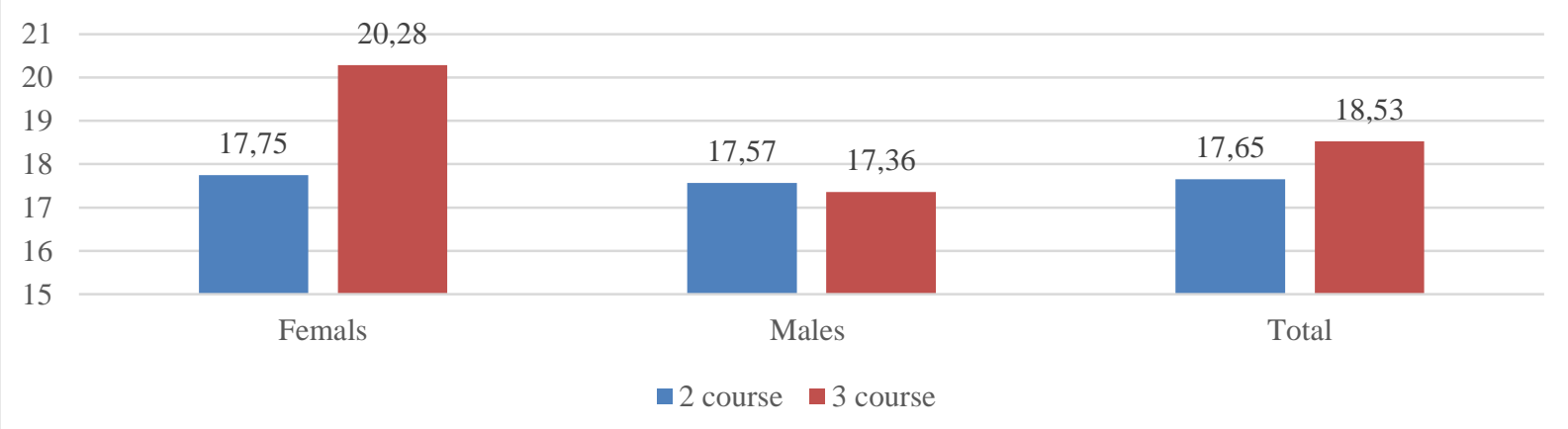

Figure 7. Degree of academic motivation for $2^{\text {nd }}$ and $3^{\text {rd }}$ year students (in points)

Assumptions about this result are within the guesswork. They could be explained on the one hand with the change in generations and their way of learning.

The conclusions drawn from the analyzes made are:

1. If an analysis is made of the assertions that received the highest agreement rate for third-year students, first, with $84.21 \%$ - "I'm trying to get a lasting knowledge of all the main disciplines." Secondly, 78.95\% disagrees with the statement that everything they learn is uninteresting. Thirdly, 52.63\% is the statements that they want to have high success in all disciplines studied. The first two statements are an indicator of an active attitude towards learning.

2. In second-year students, the indicator of active attitudes towards learning is again leading. With $80.77 \%$, they express their disagreement that what they are learning is uninteresting. $65.38 \%$ follow the assertion that they keep regular notes during the lectures, followed by $61.54 \%$ that they are trying to gain knowledge on all the main subjects.

3. The overall conclusion is that for all students in Physical Education and Sport, both courses, learning is paramount. There are no differences in gender.

Today, when information is everywhere when young people learn both in their audiences and at work, the dynamics of academic motivation is also great. Let's not forget the fact that the scale was developed in 2005. Today, when the time required different educational changes, it could be improved. A constantly long-term study would make it possible to trace the attitudes of the students of Physical Education and Sport to the Faculty of Education of the University of Sofia at the University of Sofia to studying. The comparison with the results of other universities and close specialties would give a fuller picture of the degree of academic motivation of students throughout the professional field.

\section{REFERENCES}

1. Antonova, M. Impact of specialized volleyball training tools on non-directional students. MNPK „Interaction of the teacher and the student in the conditions of the university education: problems and perspectives". Collection of Scientific Papers, First Book, ed. EXC-PRESS, Kiten. 2017. (in bulgarian)

2. Dzhambazova, E. \& Marinova, E. Specifics of some main skills of the physical education and sports teacher in primary schools depending on the curriculum. Research in Kinesiology. №2, ISSN 18577679, pp. 109-117. 2014.

3. Dzhambazova, E. \& Penkova, Ev. Study of the preferred qualities of the teacher of physical education and sport by elementary school pupils. Electronic magazine for science, culture and education. FNPP. SU "St. Kliment Ohridski ", №3, ISSN 23676396, p. 92-97. 2015. (in bulgarian)

4. Georgiev, Zh. Investigation of the anthropometric indicators of students from the University of Forestry after an applied 
model for development of physical capacity. Sports and Science, 6, pp. 112133. 2017. (in bulgarian)

5. Ignatov, G. The vision of the university lecturer according to the students of specialty "Physical education and sport" at the Sofia University "St. Kliment Ohridski ". Collection of scientific reports. Theory and practice of the psychological and pedagogical training of the specialist at the university. Association of Professors from the Slavonic Countries. Second book. Tom first. Publishing house "EKS-PRESS" Gabrovo, pp. 497-505. 2016. (in bulgarian)

6. Ilieva, I. Content and forms of sports events organization with students from the University of Ruse "ANGEL KANCHEV", Activities in Physical Education and Sport 2016, Vol. 6, №1, pp. 51-53. 2016.

7. Ilieva, I., Doncheva, Y. Analysis of Attitudes towards Physical Education and Sports of Students of Pre-School and Primary School Pedagogy at Rousse University. Scientific papers at the University of Rousse. volume 52, series 8.2, pp. 123-130. 2013. (in bulgarian)

8. Ivanova, V. Aspects of developing reflection among students in their methodical preparation. Yearbook of Pedagogical Faculty. Stara Zagora, Ed. Thracian University, p.12, pp. 140-147. 2012. (in bulgarian)

9. Marcheva, P. Musico-pedagogical training of students - future kindergarten teachers a comparative analysis (based on the example of the Pleven College of education, Bulgaria, and The Aleksinac College for kindergarten teachers, Serbia). In: International Journal KNOWLEDGE, Institute of Knowledge Management, Scientific Papers Vol.20.1, Education and Social Sciences - Knowledge in Practice, Skopje, EBSCO HOST Global Impact \& Quality Factor 1.322, pp. 347-353, ISSN 2545-4439. 2016.

10.Peltekova, I. Experience of students of the Sofia University involved in sports in the
IGNATOV G., et al. period of study. Materials VI-Int. Scientific Practical Conf. TULA, ISBN 978-5-87954644-6, Ed. TSPU them, L.N. Tolstoy, with. 390-383. 2011 (in russian)

11.Peltekova, I. Formation of competences of students with vocational qualification "teacher of physical education" in the process of their practical training. MKK, Kiten. "Psychological-pedagogical problems of the development of the personality of the professional in the conditions of university education" Collection of scientific papers - first book, volume 1, ISBN 978-954-490-448-7; Ed. ЕКС-ПРЕС - Gabrovo, pp. 464-468. 2014. (in bulgarian)

12.Petkova, I. The training in the subject "Physical education and sport" of the Faculty of Primary and Pre-school Pedagogy - the opinion of the students. Fifth International Scientific Conference. Optimization and innovation in the training process. Sofia University "St. Kliment Ohridski ". Department of Sport University Press "St. Kliment Ohridski ". Sofia, pp. 181-187. 2013. (in bulgarian)

13.Radoslavova, M., A. Velichkov. Psychodiagnostic methods. Publishing House Pandora Prim. 2005. (in bulgarian)

14.Topolska, E. Professional - pedagogical preparation of students - future children's teachers for work with children with special educational needs /comparative research/ International Journal KNOWLEDGE, Institute of Knowledge Management, Scientific Papers Vol.20.1, Education and Social Sciences - Knowledge in Practice, Skopje, EBSCO HOST Global Impact \& Quality Factor 1.322, pp. 413-418, ISSN 2545-4439. 2017.

15.Tumanova, B. Investigation of the ability to increase the ability of the students through the means of swimming sport. Sat. "Modern Trends of Physical Education and Sports", ISBN 1314-2275, VIS, C, p. 7-10. 2016. (in bulgarian) 